\title{
ROL DEL TRIBUNAL CONSTITUCIONAL PERUANO \\ EN MATERIA LABORAL Y PREVISIONAL \\ (ENSAYO)
}

\section{LEOPOLDO GAMARRA VÍLCHEZ* \\ lgamarra@congreso.gob.pe}

Recibido: 20 de setiembre 2018
Aceptado: 10 de enero 2019

\section{Resumen}

La creación del Tribunal Constitucional, en el Perú, no cuenta con mucho tiempo de funcionamiento. El TC tiene como antecedente la creación del Tribunal de Garantías Constitucionales en un contexto muy especial por la Constitución de 1979, que entró en funciones en 1982. Con la Constitución de 1993 se precisó sus funciones; así, en nuestro sistema jurídico recién desde el 2000 contamos con sentencias relevantes del TC en defensa de la constitucionalidad de los derechos fundamentales de los ciudadanos, especialmente de los derechos laborales y previsionales. De este modo, en el presente artículo se pretende desarrollar el rol del TC en materia laboral y previsional, específicamente en los derechos fundamentales de carácter individual, colectivo, procesal y seguridad social como partes sustanciales del Derecho del Trabajo.

Palabras clave: Tribunal Constitucional - Derecho del Trabajo - Derecho Previsional.

\begin{abstract}
The creation of the Constitutional Court, in Peru, does not have much operating time. The TC has as background the creation of the Court of Constitutional Guarantees in a very special context by the Constitution of 1979, which came into office in 1982. With the Constitution of 1993 its functions were specified; thus, in our legal system, since 2000, we have received relevant judgments from the Constitutional Court in defense of the constitutionality of the fundamental rights of citizens, especially labor and social security rights. In this way, this monograph aims to develop the role of the TC in labor matters, specifically in the fundamental rights of individual, collective, procedural and social security as substantial parts of Labor Law.
\end{abstract}

Keywords: Constitutional Court - Labor Law - Social Security Law.

*Docente UNMSM y USMP 


\section{Introducción}

Con este artículo queremos contribuir con la Revista Alternativa financiera de la Facultad de Ciencias Contables Económicas y Financieras de la Universidad San Martín de Porres, desarrollando un tema muy especial como es el rol del Tribunal Constitucional peruano en materia laboral y previsional.

Como sabemos, la creación del Tribunal Constitucional (en adelante TC), en nuestro país, no tiene mucho tiempo de funcionamiento. El TC tiene como antecedente la creación del Tribunal de Garantías Constitucionales (en adelante TGC) en un contexto muy especial por la Constitución de 1979 y entró en funciones en 1982. Con la Constitución de 1993 se precisó sus funciones; así, en nuestro sistema jurídico recién desde el 2000 contamos con sentencias relevantes del TC en defensa de la constitucionalidad de los derechos fundamentales de los ciudadanos, especialmente de los derechos laborales y previsionales.

De este modo, se pretende desarrollar el rol del TC en materia laboral, específicamente en los derechos fundamentales de carácter individual y colectivo, como partes sustanciales del Derecho del Trabajo asimismo, de los derechos previsionales de los trabajadores en general.

Este contenido se organiza en cuatro partes, además de la introducción y las conclusiones: en la primera parte, se desarrolla la creación del Tribunal Constitucional a fines de la década del setenta, en el contexto de grandes cambios económicos y sociales; en la segunda, se analiza la jurisprudencia del TC en materia de derechos laborales, especialmente a partir del 2000; en la tercera parte, se muestran los criterios garantistas laborales utilizados por el TC, específicamente los más importantes en materia de derechos individuales y colectivos; y finalmente, señalaremos algunas ideas a manera de conclusión.

\section{Antecedentes: creación del Tribunal de Garantías Constitucionales}

En el Perú, la década del setenta marcó fuertemente la coyuntura de los años posteriores. Así, los cambios económicos y sociales, con todos los problemas e insuficiencias, comenzaron a exigir su cumplimiento a través de reivindicaciones sociales concretas que se plasmaron en la Constitución de 1979. Además, en la propia Constitución se crearon mecanismos jurídicos para garantizar su cumplimiento, como el Tribunal de Garantías Constitucionales ${ }^{1}$. Por ello, trataremos los grandes cambios como contexto de su creación, luego el paso al TC en la década 90 y en qué consiste su naturaleza y rol.

\subsection{Los grandes cambios de los años 70}

Los años 70 fueron marcados por la coyuntura de los sesenta. Existía un ambiente de necesidad de grandes cambios y rechazo a la situación existente y se sostenía que la situación social debía transformarse para que la justicia pudiera existir en el país ${ }^{2}$. En

\footnotetext{
${ }^{1}$ Como órgano de control de la Constitución (Art. 296) y con facultad para declarar la inconstitucionalidad parcial o total de las leyes, decretos legislativos, normas regionales, etc. (Art.298).

${ }^{2}$ A nivel internacional, el año 68, por ejemplo, fue un año simbólico en la aparición de hechos o proyectos alternativos de vida. Así, tenemos el mayo francés, el movimiento hippie y la revuelta de Praga contra el
} 
términos políticos, "la revolución de la fuerza armada" de Velasco Alvarado fue un proceso de cambios autoritarios, pero socialmente democratizantes.

Ese proceso tuvo su máxima expresión en el período de 1968-1975 porque se llegó a cancelar la oligarquía como forma de dominación política y social, que permitió llevar a cabo una estrategia de desarrollo por medio de la política de sustitución de importaciones. Ello significó una importante alteración social y económica: "el proyecto militar se proponía de manera general, combinar la acumulación capitalista del Estado y la del sector privado a fin de ampliar, profundizar y homogeneizar el mercado interno, con la consiguiente integración económica y social. (Cotler, 1980, p. 51).

Así, el trabajo fue promovido como derecho, dignidad y deber de todo ciudadano. De este modo, se aprobaron importantes dispositivos legales que modificaron sustancialmente la legislación laboral" ${ }^{3}$ con "relaciones laborales justas que compatibilizan la dignidad, seguridad y bienestar del trabajo con la eficiencia del centro de trabajo y desarrollo socioeconómico del país"4. Y el año de 1975, los propios militares retiraron a Velasco y prepararon su retiro de Gobierno con las elecciones para la Asamblea Constituyente de 1978 en donde se aprobó la nueva Constitución de 1979.

\subsection{El paso del Tribunal de Garantías Constitucionales al Tribunal Constitucional}

El TGC fue creado, en un contexto muy especial, por la Constitución de 1979 y entró en funciones en 1982. Logró protagonismo político entre agosto de 1991 y marzo de 1992 al declarar inconstitucional los Decretos Legislativos 650, 651,674 y la Ley 25334, cuyos temas de fondo eran la liberalización económica en oposición a la Constitución de 1979.

El 5 de abril de 1992, con el golpe de Estado de Fujimori, se cerró el TGC. De este modo, varios años no se contó con el control constitucional necesario. Es decir, si bien con la nueva Constitución de 1993 se creó el TC pero no entró en vigencia hasta 1995 y esto porque "durante 1994, debido a la falta de promulgación de la Ley Orgánica del Tribunal Constitucional (...) y debido a la falta de nombramiento de los magistrados y a la expedición de una ley orgánica de garantías constitucionales...”. (Landa, 1995, p. 79)

Además, es interesante recordar que en "los primeros anteproyectos elaborados por el Congreso Constituyente Democrático en 1993, no se incorporó al Tribunal Constitucional; sino, solo a partir del debate en el pleno de CCD encargado de la aprobación final del texto constitucional a ser puesto a votación para referéndum. Esto puso en evidencia dos cosas: por un lado, la intención de la mayoría parlamentaria fujimorista que la Corte Suprema asuma la función de jurisdicción constitucional en los primeros proyectos y, por otro lado, que al gobierno no le era funcional la existencia de un Tribunal Constitucional autónomo, que se encargue del control constitucional del

régimen pro-soviético. La impresión era que un mundo nuevo estaba surgiendo como un proceso de liberación humana.

3 Así, tenemos importantes normas como el Decreto Ley 18471 del 10 de noviembre de 1970, sobre estabilidad laboral para el régimen privado. En materia colectiva, se dictaron medidas que buscaban su modernización, especialmente sobre negociación y convención colectiva.

${ }^{4}$ Objetivo 22 del Plan de Gobierno Revolucionario de la Fuerza Armada, Plan Inca, 3 de octubre de 1968. 
poder, sino más bien un dócil Poder Judicial que asuma la tarea de controlar judicialmente a los poderes públicos”. (Landa, Ob. Ci. p.78).

\subsection{Naturaleza y rol del Tribunal Constitucional}

En la doctrina constitucional, los órganos encargados de la constitucionalidad tienen una naturaleza binaria: jurídico y político. Así, en el caso peruano el TC ha señalado que "dada su condición de supremo intérprete sustenta la validez funcional de su actuación justamente en la naturaleza de la Constitución.

Desde el punto de vista estructural y funcional, la Constitución es la norma que fundamenta el sistema jurídico y político..."5.

En tal sentido, el rol del Tribunal se plasma de dos modos: como regulador, cuando se dirimen conflictos en general y como legislador "negativo", cuando se declara fundada una inconstitucionalidad. Y el elemento político "queda patentizado, en su esfuerzo para preservar el orden constitucional y los derechos y las libertades ciudadanas. En ese contexto opera "como un poder moderador y corrector de los excesos o incurias funcionales de los poderes constituidos". (García, 2005 p. 17).

Por otro lado, el TC peruano estableció también la tipología y los efectos de la jurisprudencia constitucional ${ }^{6}$. Así, se establece dos clasificaciones: la primera, comprende las sentencias de especie y de principio; la segunda, las sentencias estimativas que pueden ser de simple anulación, interpretativas propiamente dichas e interpretativas manipulativas, y las sentencias desestimativas que pueden ser por rechazo simple o por sentido interpretativo.

De la mencionada clasificación debemos resaltar las sentencias de principio, que son las que determinan propiamente la jurisprudencia constitucional en tanto interpretan el alcance y el sentido de las normas constitucionales y constituyen los precedentes vinculantes ${ }^{7}$. Estas sentencias se refieren a temas relevantes para el país como interés colectivo para la convivencia pacífica.

\section{El contexto que determinó la jurisprudencia del TC en materia laboral y social}

A inicios de los 90, el país ingresó a un nuevo momento histórico, a un nuevo tiempo de problemas y profundos cambios económicos, sociales y políticos muy diferentes a los años anteriores. Por ello, es necesario referirnos a los cambios de la década 90, especialmente a la reforma laboral para explicar luego en qué consiste la jurisprudencia constitucional en materia laboral y previsional.

\footnotetext{
${ }^{5}$ Expediente 0050 - 2004 y otros AI/TC - 2005, en el proceso de inconstitucionalidad seguido por los Colegios de Abogados del Cusco y del Callao y más de cinco mil ciudadanos contra la Ley 27600.

${ }^{6}$ Exp. 004 - 2004 - CC/TC, en el proceso de competencia entre el Poder Judicial y el Poder Ejecutivo.

${ }^{7}$ Podemos citar en materia laboral, que desarrollaremos más adelante: Expediente 1124-2001-AA/TC, FETRATEL en contra de Telefónica; Exp. 976-2001-AA/TC, Eusebio Llanos Huasco contra Telefónica; Exp. 206-2005-PA/TC, Antonio Baylos Flores en contra E.P.S. EMAPA. En materia previsional: Expediente 0010-2002-AI/TC, en el proceso seguido contra los Decretos Leyes 25475, 25659, 25708 y 25880; Exp. 0152001-AI/TC y Exp. 024-2001-AI/TC, en los procesos seguidos contra el Decreto de Urgencia 055-2001.
} 


\subsection{Los noventa y lo mucho que ha cambiado en el mundo}

A fines de los 80, en el mundo, se argumentó que el Estado genera gastos improductivos y se planteó retornar al Estado garante del libre mercado, sosteniendo que, en la medida que se haga a un lado, funcionará la economía; se "propone la universalización de las leyes económicas, la exigencia de la internacionalización de las economías para la modernización de las sociedades..." (Ugarteche, 1997, p. 20) y el libre juego de las leyes de la competencia y el proceso de la privatización de empresas públicas ${ }^{8}$.

Con la globalización económica llegaron al mercado mundial nuevas culturas empresariales, nuevas savoir faire y nuevas escuelas ${ }^{9}$ de organización que significó la flexibilización del mercado de trabajo en cuanto a la producción de bienes y servicios. Es decir, esa flexibilización se desarrolló paralelamente al proceso de globalización económica, afectando ambos el funcionamiento de los Estados nacionales, las empresas y los sindicatos ${ }^{10}$.

El fenómeno empezó en América Latina, con el neoliberalismo como ideología y formación socioeconómica, fue extremo, propiamente fue desregulación o desreglamentación que suponía "una drástica reducción de niveles de protección legal, e incluso colectiva, con supresión de normas, para conseguir que las condiciones de trabajo se fijen con el libre acuerdo de las partes, retornando al juego del mercado de trabajo.

En el fondo, lo que late en la desregulación, es un deseo de volver a los orígenes, de retorno a los viejos dogmas de la doctrina liberal pura; (...) la desregulación supone poner en duda los principios mismos del Derecho del Trabajo. La desregulación requiere en alguna medida y de forma paradójica la intervención estatal, a través de las leyes que se limiten a asegurar el libre juego de la autonomía individual...”. (Blasco 1995, p. 31 y 32).

Un importante estudio de la OIT, (Vega M.L. 2001) sobre el tema, señala que en Argentina y el Perú las reformas han sido las más profundas y han tenido un carácter marcadamente flexibilizador; asimismo, se puede observar en el siguiente cuadro, la orientación de las reformas laborales en otros países de América Latina.

\footnotetext{
8 Como implementación de las políticas del Fondo Monetario Internacional, el Banco Mundial y la Organización Mundial del Comercio, inspiradas en el Consenso de Washington, como un listado de políticas económicas considerados durante los años 90, descritos por Joseph Stiglitz en su obra El malestar en la globalización, Ed. Taurus, Madrid, 2002.

${ }^{9}$ Además del modelo alemán en los años 70 y 80 tuvieron notoriedad los modelos italiano, sueco y japonés. Pero en todos significaba flexibilización laboral que ha llevado a una redistribución más inequitativa del producto y de los sistemas de producción.

${ }^{10}$ En cuanto a la evolución y tendencias de las relaciones de trabajo en Europa frente a la crisis, a la reestructuración económica y la globalización, ver el libro de Georges Spyropoulos, La relación del trabajo en Europa: tendencias actuales y perspectivas futuras, Buenos Aires, Asociación Trabajo y Sociedad, 1997. Y para América Latina, como texto general globalización, ciudadanía y política social en América Latina: tensiones y contradicciones, Andrés Pérez Baltodano (Edit., Venezuela: Nueva Sociedad, 1997).
} 
Tabla 1

Orientación general de las reformas laborales en América Latina

\begin{tabular}{|l|l|l|l|}
\hline $\begin{array}{l}\text { Reformas } \\
\text { profundas } \\
\text { marcadamente } \\
\text { flexibilizadoras }\end{array}$ & $\begin{array}{l}\text { Reformas menos } \\
\text { extensas en } \\
\text { perspectiva } \\
\text { flexibilizadora }\end{array}$ & $\begin{array}{l}\text { Reformas } \\
\text { flexibilizadoras de } \\
\text { menor corte }\end{array}$ & $\begin{array}{l}\text { No se aplicaron } \\
\text { reformas pero sí } \\
\text { cambios con } \\
\text { tendencia } \\
\text { flexibilizadora }\end{array}$ \\
\hline Argentina & Brasil & Chile & Bolivia \\
Perú & Colombia & Ecuador \\
& Panamá & Guatemala & Honduras \\
& & Nepúxico \\
& & Romulica & Uruguay \\
& & Venezuela & El Salvador \\
& & & Paraguay \\
\end{tabular}

En el Perú, en los años 80, la situación laboral se agravó con una economía profundamente excluyente en la que estalló la hiperinflación pulverizando todos los registros (Schuldt y Pease, 1980-1981). Además, "el fenómeno de la violencia política se entrelazó desde inicios de los 80 creando complejas situaciones que acentuaron los efectos de la crisis económica" (Manrique, 2002, p. 260). El resultado fue el debilitamiento y desaparición de muchas organizaciones sindicales, en momentos que éstas atravesaban por una crisis ideológica, organizativa y de representación.

\subsection{La reforma laboral flexibilizadora}

La reforma laboral flexibilizadora en el Perú iniciada en 1991, abarcó cuatro ámbitos fundamentales: derechos individuales, derechos colectivos, normas procesales y dispositivos sobre seguridad social a través de medidas que han modificado la relación entre trabajador y empleador, hacia un nuevo Derecho del Trabajo y una nueva Seguridad Social. (Gamarra y Alemán 1998).

Y en 1993, luego de la interrupción del régimen democrático, se adoptó una nueva Constitución Política que reguló sensiblemente a la baja los derechos laborales y sociales respecto a la Constitución de 1979. Y se ubica, dentro de la clasificación tradicional, como "producto de un esfuerzo deliberado del Estado que establece de una vez para siempre un cuerpo de provisiones coherentes, de acuerdo con las cuales y por las cuales su gobierno se ha de establecer y regir". (Bryce, 1988, p. 7).

En materia de derechos individuales, se reformó la institución central del Derecho Laboral: el contrato de trabajo, de donde provienen todos los derechos de los trabajadores. Por ello, el epicentro de la reforma fue el contrato de trabajo ${ }^{11}$. Y el principal efecto fue la

\footnotetext{
11 Por otro lado, la flexibilización del salario tuvo dos orígenes: uno de carácter micro y otro macro. El primero, derivado de la puesta en práctica de nuevas formas organizativas que no se corresponden con la segmentación del trabajo que caracterizó el sistema tayloristafordista y que permitía asignar la remuneración de acuerdo a un puesto de trabajo determinado. El segundo, los nuevos sistemas de remuneración, de carácter macro, es el que está teniendo mayores consecuencias sobre los ingresos de los trabajadores. La internacionalización de los mercados, como parte de la globalización de la economía, ha conducido a que la
} 
multiplicidad de formas de contratación temporal, con requisitos legales tan amplios que permiten su utilización casi en cualquier circunstancia. Esta temporalidad es entendida como precariedad en el empleo, tanto porque aumenta la incertidumbre en los trabajadores e "introduce un elemento de ineficiencia en la relación laboral, ya que el trabajador empleará parte de su tiempo (y de su capacidad productiva) en protegerse ante una posible terminación del contrato..." (Garavito, 1996, p. 18).

Así, en cuanto a formas de contratación, el Perú pasó a tener uno de los mercados de trabajo más flexibles del ámbito latinoamericano. El paso de un mercado laboral rígido a un mercado laboral flexible como resultado de la aplicación de la Ley de Fomento del Empleo (Decreto Legislativo 728 de noviembre de 1991 y sus modificaciones). Esto provocó que el desempleo se agravara no de quienes quieren trabajar por primera vez, sino como el resultado de la rotación y el intento de regresar de quienes ya han tenido experiencia, porque los contratos tienen poca duración.

En cuanto a los derechos colectivos, podemos señalar, como resultado de la reforma laboral, el debilitamiento y desaparición de muchas organizaciones sindicales, en momentos que éstas atravesaban por una crisis ideológica, organizativa y de representación (Villavicencio, 1999). Esto fue efecto de la aplicación del Decreto Ley 25593 del 2 de julio de 1992, que establecía limitaciones a la libertad sindical. (Boza, 1992, p. 14) En cuanto a la huelga podemos señalar que, durante el periodo estudiado, han disminuido ostensiblemente. Sin embargo, la conflictividad ha estado latente sin manifestarse por el cambio de reglas de las relaciones laborales (Ercilio y Valladares 2013).

Respecto a la administración de justicia laboral, la reforma no ha logrado superar el problema de la autonomía procesal. Con la Ley 26636 del 24 de junio de 1996, se ha vuelto a las normas civiles a pesar de que el procedimiento laboral debe responder a otros criterios y contar con principios propios. Si bien el procedimiento laboral tiene, en gran parte, similitud con el procedimiento común, debe excluirse la utilización de normas civiles, porque en el procedimiento civil no se encuentra tan desarrollado el aspecto social como en el laboral ${ }^{12}$. En enero del 2010 se aprobó la Nueva Ley Procesal del Trabajo, Ley 29497 que derogó la anterior.

Finalmente, el 6 de diciembre de 1992, se creó el Sistema Privado de Pensiones (SPP), mediante el Decreto Ley 25897, con la finalidad de contribuir al desarrollo y fortalecimiento del sistema previsional en el país ${ }^{13}$. El SPP surge como una alternativa al Sistema Nacional de Pensiones (SNP), de tal forma que el trabajador pueda decidir si desea permanecer en el

expansión de los aparatos productivos se haga en función del mercado externo, rompiéndose, por tanto, la relación que existía anteriormente entre salario y consumo.

12 "Frente a la creciente autonomía de los diferentes sectores de la vida social propiciada por el fenómeno de la globalización con sus racionalidades específicas y muchas veces incompatibles entre sí que conducen a la ampliación de los sistemas auto organizados y auto-regulados"; como señala el profesor de filosofía y sociología jurídica de la Universidad de Sao Paulo - Brasil, José Eduardo Faria en su artículo "La globalización y el futuro de la justicia", Revista Trabajo y Seguridad Social, Lima, octubre 1997, p. 64.

${ }^{13}$ Un documento muy importante es el especial, sobre el Sistema Privado de Pensiones, dirigido por Luis Aparicio Valdez, en la Revista Análisis Laboral, vol. XXV, № 283, enero 2001. 
SNP o afiliarse al $\mathrm{SPP}^{14}$. Sin embargo, los costos hundidos de tipo endógeno han llevado a encarecer el servicio ${ }^{15}$, debido que estos gastos constituyen la principal fuente de diferenciación ante una inexistencia de competencia de precios que llevó a una reforma el año 2012 con la Ley 29903, Ley de Reforma del Sistema Privado de Pensiones.

\section{Criterios jurídicos garantistas utilizados por el Tribunal Constitucional}

La jurisprudencia constitucional ha tenido y tiene un rol activo. Esta labor ha salido a relucir en la justicia constitucional impartida por nuestro Tribunal Constitucional, la cual ha destacado desde el inicio de su funcionamiento institucional. Como supremo intérprete de la Constitución y defensor de los derechos consagrados en la Constitución, comprende en su texto a los derechos del trabajo. Así, en las últimas décadas, ha sido el Tribunal Constitucional quien ha dictaminado criterios garantistas que han modificado en gran parte las disposiciones con carácter flexibilizador que contienen nuestras leyes laborales. Entonces, corresponde ahora efectuar una visión breve y panorámica sobre los criterios garantistas exclusivamente utilizados por el Tribunal Constitucional en los precedentes vinculantes específicos sobre los derechos laborales en el ordenamiento peruano.

Cabe señalar, que el precedente constitucional vinculante "es aquella regla jurídica expuesta en un caso particular y concreto que el Tribunal Constitucional decide establecer como regla general; y, que, por ende, deviene en parámetro normativo para la resolución de futuros procesos de naturaleza homóloga" 16 . De ahí la importancia de los precedentes en cuanto a los efectos que tienen similares a una ley. El propio TC peruano señala cuáles son los precedentes vinculantes en materia laboral y previsional ${ }^{17}$.

\subsection{En materia de los derechos fundamentales laborales de carácter individual}

Los derechos fundamentales constitucionalmente reconocidos no sólo abarcan el listado del artículo 2 de nuestra Constitución, sino todos aquellos derechos de la persona consagrados en instrumentos internacionales (Tratados, Declaraciones, etc.) de los que el Perú forma parte; todos los cuales pueden ser considerados derechos con rango constitucional en nuestro ordenamiento jurídico. Más aún el artículo 3 de nuestra Constitución extiende el rango constitucional no solo a los derechos expresamente reconocidos en su artículo 2 sino también a todos los demás derechos fundamentales contenidos en otros instrumentos (entiéndase tratados) obligatorios para el Perú. (Novak, 2005, p.766).

Al respecto, el Tribunal Constitucional ha señalado que (...) en materia de derechos fundamentales, las normas que los reconocen, regulan o limitan deben interpretarse de

\footnotetext{
${ }^{14}$ El Perú fue el segundo país en la región, después de Chile, en crear un SPP.

${ }^{15} \mathrm{Un}$ sistema pensionario depende fundamentalmente de varios factores de orden estructural: la composición de edades (esperanza de vida), el funcionamiento de sus mercados laborales, el tamaño de la fuerza laboral activa y sus niveles de productividad y salario, así como la cuantía de la cotización y la existencia efectiva de un

a planilla con beneficios sociales

${ }^{16}$ Domingo García Belaunde, Diccionario de Jurisprudencia Constitucional.

17 Aunque, algunos autores, consideran críticamente que, en el caso laboral, el Tribunal Constitucional ha tomado un rol legislador, tanto en derechos individuales como colectivos. Esto desbordaría sus atribuciones.
} 
conformidad con los tratados sobre derechos humanos (...) no solo es una exigencia que se deriva directamente de la IV Disposición Final y Transitoria de la Constitución, sino también del hecho de que los tratados, una vez ratificados por el Estado peruano, forman parte del derecho nacional ${ }^{18}$.

Incluso el Tribunal Constitucional considera la supremacía del Tratado de Derechos Humanos: (...) podría argumentarse que este papel rector o delimitador de los tratados sobre derechos humanos, para efectos de la interpretación del contenido y alcances de los derechos constitucionales, los colocaría en una suerte de rango o posición supraconstitucional" "19. Por otro lado, la Convención de Viena, sobre derechos de los Tratados, en su artículo 27 sostiene que los Estados planteen excusas sobre limitaciones de su normatividad interna para dejar de cumplir con los tratados: “(...) no podrá invocar las disposiciones de su derecho interno como justificación del incumplimiento de un tratado”. La Corte Interamericana en ese sentido ha fijado posición, llegando a señalar que ni siquiera la normatividad de la Constitución del Estado debe ser motivo para no cumplir con las obligaciones de los Tratados de Derechos Humanos: “(...) Según el derecho internacional las obligaciones que éste impone deben ser cumplidas de buena $f^{20}$ y no puede invocarse para su incumplimiento el derecho interno (...) aun tratándose de disposiciones de carácter constitucional" $21{ }^{22}$. Por ello, el TC en estas dos últimas décadas prácticamente reformó casi todos los derechos individuales fundamentales, como se puede observar en la siguiente tabla

Tabla 2

Sentencias sobre derechos fundamentales laborales de carácter individual

\begin{tabular}{|c|c|l|}
\hline Carácter & Derecho & \multicolumn{1}{c|}{ Sentencias } \\
\hline \multirow{3}{*}{$\begin{array}{c}\text { DERECHOS } \\
\text { FUNDAMENTALES }\end{array}$} & Libertad de Trabajo & $\begin{array}{l}\text { EXP. 0008-2003-AI/TC, Fund. 26 } \\
\text { EXP. 0661-04-AA/TC, Sentencia }\end{array}$ \\
\cline { 2 - 3 } LABORALES DE & \multirow{2}{*}{ Derecho al Trabajo } & EXP. 0008-2005-AI/TC, Fund. 18 \\
CARÁCTER & EXP. 1124-2001-AA/TC, Fund. 12 \\
INDIVIDUAL & $\begin{array}{l}\text { EXP. 0008-2005-PI/TC, Fund. 23 } \\
\text { y no discriminación } \\
\text { en el trabajo }\end{array}$ & $\begin{array}{l}\text { EXP. 2510-2002-AA/TC, Sentencia } \\
\text { EXP. 01875-2006-PA/TC, Sentencia }\end{array}$ \\
& $\begin{array}{l}\text { EXP. 1124-2001-AA/TC, Fund. 11 } \\
\text { EXP. 0666-2004-AA/TC, Sentencia }\end{array}$ \\
& EXP. 0217-2004-AA/TC, Sentencia \\
& EXP. 0895-2001-AA/TC, Sentencia \\
\hline
\end{tabular}

\footnotetext{
${ }^{18}$ Sentencia del Tribunal Constitucional, Expediente 1230-2002-HC/TC del 20.06.2002.

${ }^{19}$ Ibídem.

${ }^{20} \mathrm{El}$ artículo 26 señala "Pacta sunt servanda". Todo tratado en vigor obliga a las partes y debe ser cumplido por ellas de buena fe.

${ }^{21}$ Opinión Consultiva de la Corte interamericana de Derechos Humanos del 09.12.94, Párrafo 35.

${ }^{22}$ En general, "los tratados en materia de derechos humanos, tienen una jerarquía no solo constitucional, sino que también gozan de una fuerza material constitucional. Lo cual se extiende, formalmente, cuando al incorporar al derecho interno un tratado modificatorio de disposiciones constitucionales, este debe ser aprobado, previamente, por el Congreso, siguiendo las normas establecidas para la reforma constitucional, antes de su ratificación por el Presidente de la República. Ello, ciertamente se condice con la tendencia histórica de la supremacía del Derecho Internacional sobre el Derecho Interno..." (César Landa, Tribunal Constitucional y Estado Democrático, Palestra, Segunda Edición, 2003, p. 787).
} 


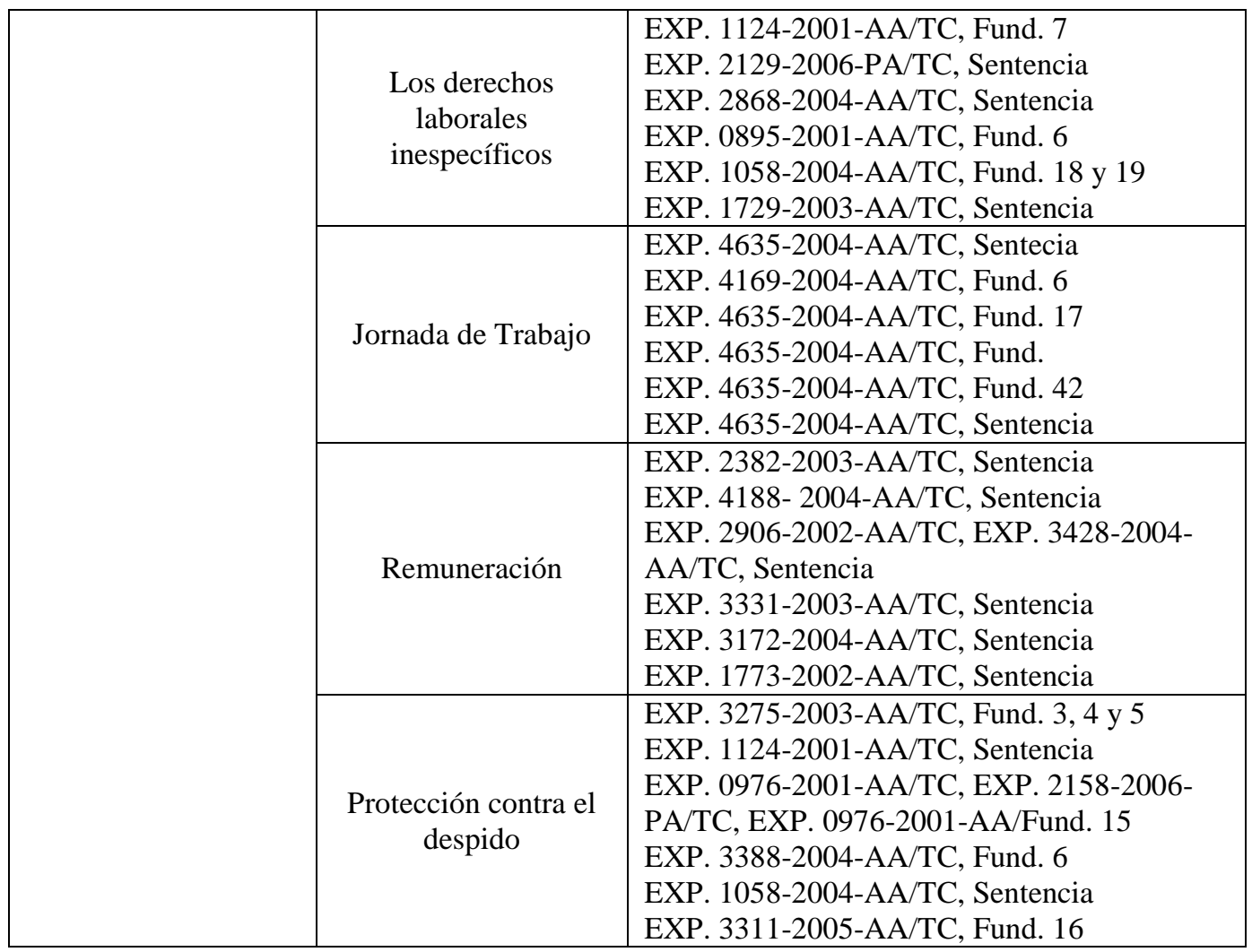

Fuente: Jurisprudencia y Doctrina Constitucional Laboral, Tribunal Constitucional del Perú, Centro de Estudios Constitucionales.

Sin embargo, solo trataremos los cambios emblemáticos que realizó el TC en cumplimiento de su rol fundamental que es resolver las acciones de inconstitucionalidad contra las normas legales. En ese sentido, podemos rescatar, en primer lugar, el caso de la figura del despido. En donde, se encuentra la STC 1124-2001-AA/TC, de fecha 11 de julio del 2002, promovido por el Sindicato Único de Trabajadores de Telefónica del Perú y la 1971Federación de Trabajadores de Telefónica del Perú S.A., contra Telefónica del Perú S.A.

Y el llamado caso Huasco recaído en la STC 976-2001-AA/TC, de fecha 13 de marzo del 2003. Los cuales fijaron principios y clases del despido. Con ello se configuraron el despido incausado, fraudulento y nulo dejando de lado el denominado despido arbitrario, con el fundamento que señaló que en ningún sistema democrático se podría concebir un acto arbitrario.

Estos casos emblemáticos tuvieron también serias críticas. La más reciente fue hecha por Jaramillo, investigador del Grupo de Análisis para el Desarrollo (Grade). En dicho estudio, se señala como causa principal de la crecida de contratos determinados en nuestro país la sentencia del Tribunal Constitucional sobre el despido arbitrario (Grade 2017). Es decir, "en el año 2015, dicho fallo habría costado la creación de poco más de 900 mil empleos con contratos indefinidos, que terminaron siendo temporales ante la imposibilidad práctica de despedir" (Jaramillo, 2001-2011). Es decir, la temporalidad se ha convertido en un problema relevante puesto que, con mayores garantías 
constitucionales para proteger el despido de trabajadores, los empleadores se encuentran "obligados" a usar los contratos temporales.

Ante estas afirmaciones debemos de tener en cuenta que la temporalidad es un fenómeno que se acrecentó con la incorporación de los contratos sujetos a modalidad por parte del D. Leg. 728. Desde ahí, el uso de estas modalidades ha tenido un crecimiento constante.

\subsection{En materia de los derechos fundamentales laborales de carácter colectivo}

El artículo 28 de la Constitución peruana de 1993 reconoce los derechos de sindicación, negociación colectiva y huelga ${ }^{23}$. Además, en el mismo artículo, inciso 1 se establece que el Estado garantiza la organización sindical. Es decir, el Estado debe fomentar, promover, impulsar y proteger el ejercicio democrático de la libertad sindical; entonces el Estado debe tener un rol activo con relación a la organización sindical. Al igual que la Constitución española en la cual se señala que "todos tienen derecho a sindicarse libremente (...). La libertad sindical comprende el derecho a fundar sindicatos y a afiliarse al de su elección..."24.

Al respecto, la doctrina de manera unánime ha entendido que donde la Constitución reconoce el derecho a la libertad sindical, se impone una obligación de promoción, o sea, se ha interpretado en un sentido promocional que existe la responsabilidad del Estado de promover los derechos colectivos. De este modo, el Tribunal Constitucional peruano ha interpretado, en varias sentencias ${ }^{25}$, que el derecho de la libertad sindical debe garantizarse conforme con la Declaración Universal de los Derechos Humanos y con los tratados internacionales ratificados por el Perú. Además, considerando la interdependencia de los derechos colectivos, el Tribunal Constitucional considera que el Estado debe fomentar la negociación colectiva basada en el Convenio 98 de la Organización Internacional del Trabajo.

En ese sentido, "el fomento implica, entre otras acciones, que el Estado promueva las condiciones necesarias para que las partes negocien libremente, estando incluso llamado a realizar las acciones positivas que resulten necesarias para asegurar las posibilidades de desarrollo y efectividad de la negociación colectiva (...) Dado el caso, el Estado puede otorgar determinado plus de tutela, si ello se requiere para viabilizar la negociación; por ejemplo, cuando se establece el nivel de rama de actividad como el adecuado, de cara a posibilitar una verdadera negociación colectiva en el sector de construcción civil"26. (Boza, 2011, p. 78).

\footnotetext{
${ }^{23} \mathrm{Al}$ respecto, establece que "El Estado reconoce los derechos de sindicación, negociación colectiva y huelga. Cautela su ejercicio democrático...".

${ }^{24}$ Curiosamente es el mismo artículo 28 que la Constitución española y peruana utilizan para el reconocimiento de la libertad sindical.

${ }^{25}$ STC del 12 de agosto de 2005, recaída en el expediente 1124-2001-AA7TC, STC del 12 de agosto de 2005, recaída en el expediente 008-2005-PITC, STC del 5 de enero de 2005, recaída en el expediente 3311-2005PATC, STC del 26 de marzo de 2003, recaída en el expediente 0261-2003-AA7TC.

${ }^{26}$ Guillermo Boza Pro, Lecciones de Derecho del Trabajo, Fondo Editorial Pontificia Universidad Católica del Perú, Lima, 2011, p.78.
} 
En este caso también, el TC prácticamente reformó casi todos los derechos colectivos fundamentales, como se puede observar en la siguiente tabla.

Tabla 3

Sentencias sobre derechos fundamentales laborales de carácter colectivo

\begin{tabular}{|c|c|c|}
\hline Carácter & Derecho & Sentencias \\
\hline \multirow{3}{*}{$\begin{array}{l}\text { DERECHOS } \\
\text { FUNDAMENTALES } \\
\text { LABORALES DE } \\
\text { CARÁCTER } \\
\text { COLECTIVO }\end{array}$} & $\begin{array}{l}\text { Sindicación y libertad } \\
\text { sindical }\end{array}$ & $\begin{array}{l}\text { EXP. 0008-2005-PI/TC, Sentencia } \\
\text { EXP. 1469-2002-AA/TC, Sentencia } \\
\text { EXP. 0632-2001-AA/TC, Sentencia } \\
\text { EXP. 3039-2003-AA/TC, Sentencia } \\
\text { EXP. 1124-2001-AA/TC, Fund. } 8\end{array}$ \\
\hline & Negociación Colectiva & $\begin{array}{l}\text { EXP. 0008-2005-PI/TC, Fund. } 29 \\
\text { EXP. 4635-2004-AA/TC, Fund. } 39 \\
\text { EXP. 1370-2002-AA/TC, Sentencia } \\
\text { EXP. 0785-2004-AA/TC, Sentencia } \\
\text { EXP. 3039-2003-AA/TC, Fund. } 1\end{array}$ \\
\hline & Huelga & $\begin{array}{l}\text { EXP. 0008-2005-PI/TC, Sentencia } \\
\text { EXP. 3311-2005-PA/TC, Fund. } 18\end{array}$ \\
\hline
\end{tabular}

Fuente: Jurisprudencia y Doctrina Constitucional Laboral, Tribunal Constitucional del Perú, Centro de Estudios Constitucionales.

Sin embargo, solo trataremos los cambios emblemáticos. Nos referimos al derecho de negociación colectiva en el sector público que comprende específicamente el arbitraje y la negociación colectiva de remuneraciones.

Como hemos señalado, en el caso del derecho a la negociación colectiva en general $^{27}$, el Tribunal Constitucional ha señalado los alcances de este derecho reconociendo el valor del Convenio 98 para respetar el contenido esencial de la negociación colectiva ${ }^{28}$ :

"El artículo 4 del Convenio 98 constituye un principio hermenéutico fundamental al cual debe acudirse para informarse respecto del contenido esencial de la negociación

27 Este derecho "cumplió en el pasado y todavía cumple en la actualidad un rol importante en la regulación autónoma de las relaciones laborales, al establecer normas en aquellos ámbitos en los que no intervienen las normas heterónomas..." (Leopoldo Gamarra Vílchez, La negociación colectiva en el Perú: de la confrontación al diálogo social, en Diálogo y Concertación Laboral, en la Revista del Consejo Nacional de Trabajo y Promoción del Empleo, Ministerio de Trabajo y Promoción del Empleo, Año 2, $\mathrm{N}^{\circ}$ 2, junio 2016, p. 31).

${ }^{28}$ Este criterio fue asumido también por el Poder Judicial. En la Sentencia de la Tercera Sala Laboral de Lima del 31 de agosto de 2015 que declara infundada la impugnación del Laudo Arbitral 2013-2014 entre el SBN y el SINDICATO se afirma lo siguiente: "OCTAVO. Que, la demandante alega la imposibilidad de asumir los incrementos remunerativos y las condiciones de trabajo otorgadas a los trabajadores sindicalizados, en mérito a que las normas de carácter presupuestario los prohíben; sin embargo, conforme lo establece el artículo $28^{\circ}$ de la Constitución Política del Perú (...); consecuentemente acceder a mejores condiciones de trabajo o incrementos remunerativos, a través de una negociación colectiva es un Derecho Constitucional de todo trabajador_(...)" (Subrayado y negrita nuestros). 
colectiva, tomando siempre en consideración que uno de sus fines principales es mejorar las condiciones de vida y de trabajo de sus destinatarios. Por lo tanto, encontrándonos ante un derecho constitucional que debe fomentarse, promoverse o apoyarse, las restricciones a que se someta no pueden desnaturalizarlo ni afectar su contenido esencial: remuneraciones y condiciones de trabajo, y empleo y regulación de las relaciones entre los sujetos colectivos firmantes " ${ }^{29}$ (Negrita nuestros).

Sin embargo, los trabajadores de entidades públicas bajo el régimen laboral de la actividad privada, que gozaban del derecho de negociar sus condiciones económicas, con las leyes de presupuesto y la Ley Servir se les prohibían la negociación colectiva en materia salarial. Y solo se le reconocía derecho a la negociación colectiva de compensaciones no económicas y condiciones de empleo.

Con ello, se desnaturalizó el contenido mínimo del derecho a la negociación colectiva y una grave lesión al bloque de constitucionalidad de los derechos $\operatorname{colectivos}^{30}$.

Además, según la OIT se estaría incumpliendo el Convenio 98 que se puede ampliar a los empleados públicos, otorgándoles oficialmente el derecho a participar en la determinación de sus condiciones de empleo, cuya negociación colectiva se menciona como una de las modalidades posibles ${ }^{31}$.

El artículo 6 de las diversas leyes de presupuesto como la Ley 30518, Ley de Presupuesto para el año fiscal 2017, prohibían los incrementos remunerativos para los servidores públicos; siendo el caso que dicho mandato o prohibición alcanzaba al fuero $\operatorname{arbitral}^{32}$. Se trataba de restricciones o limitaciones graves del contenido salarial de la negociación colectiva. Asimismo, la Ley 30057, Ley del Servicio Civil hacía lo mismo desde el $2013^{33}$.

Así, los funcionarios públicos y sus entidades sólo podían negociar o arbitrar condiciones de trabajo, lo contrario significaría una violación de las normas presupuestales e implicaría responsabilidad para quien lo haga. Es decir, siendo las normas presupuestales de orden público, específicamente que prohíbe el incremento de

${ }^{29}$ Sentencia del 26 de marzo del 2003 recaída en el Expediente 0261-2003-AA/TC (Negociación colectiva por rama de actividad, CAPECO, Fundamento jurídico 3, 26 de marzo de 2003.

${ }^{30} \mathrm{El}$ artículo 28 de la Constitución establece que el Estado reconoce los derechos de sindicación, negociación colectiva y huelga, cautelando su ejercicio democrático, garantizando la libertad sindical; fomentando la negociación colectiva y promoviendo medios de solución pacífica de los conflictos laborales; y, regulando el derecho de huelga para que se ejerza en armonía con el interés social.

${ }^{31}$ Estudio General relativo a las relaciones laborales y la negociación colectiva en la administración pública. Tercer punto del orden del día: Informaciones y memorias sobre la aplicación de Convenios y recomendaciones. Informe de la Comisión de Expertos en Aplicación de Convenios y Recomendaciones (arts. 19, 22 y 35 de la Constitución), Informe III (Parte 1B), Oficina Internacional del Trabajo, Ginebra, 2013.

32 Específicamente, "en cuanto a la prohibición de otorgar beneficios económicos unilateralmente por el Estado, se debe apuntar que estaríamos considerando a la remuneración como un pago por servicio prestado. Ello, negaría el carácter de instrumento de inclusión social que le reconoce el artículo 24 de la Constitución..." (Elmer Arce Ortiz, ¿se debe mantener el artículo 6 del proyecto de presupuesto del 2017?, en La inconstitucionalidad del artículo 6 del Proyecto de Ley de Presupuesto 2017, Comisión de Trabajo y Seguridad Social 2016-2017 del Congreso de la República, Lima, 2017, p.28)

${ }^{33}$ Esta ley se orienta en el sentido de la competitividad, de la gestión por resultados, de una evaluación periódica y de una gestión de capacitación que permita dar continuidad a las políticas públicas. 
remuneraciones, el acto jurídico por el cual se somete al tribunal arbitral la solución del conflicto es nulo, por lo cual al tribunal arbitral le correspondería en este supuesto inhibirse del conocimiento del mismo.

Finalmente, los artículos 31.2, 40, 42, 43 e), 44 b) de la Ley del Servicio Civil (Ley 300057) y los artículos 66, 68, 76 y 78 de su Reglamento General, indicaban que la compensación mensual (remuneración mensual en las dos normas) de los servidores públicos no eran materia de negociación colectiva; que solo podían negociar condiciones de trabajo o empleo que no sean de naturaleza económica y que toda negociación que contravenía lo dispuesto sería nula de pleno derecho; asimismo, que de someterse la controversia a un arbitraje laboral, los árbitros se encontraban impedidos de pronunciarse sobre aquellas cuestiones de naturaleza económica.

En ese sentido, tanto la Ley SERVIR como su reglamento general, restringían desproporcionalmente y con carácter permanente la negociación colectiva; despojaban a la organización sindical y a los trabajadores que representa, del contenido esencial de su derecho a negociar materias salariales, en directa violación del bloque de constitucionalidad $^{34}$.

Pero, en la sentencia del Tribunal Constitucional del 3 de setiembre de 2015, recaída en los expedientes 0003-2013-PI/TC, 0004-2013-PI/TC y 0023-2013-PI/TC, se señala que:

"81. Cuando los Estados atraviesan crisis económicas, financieras o períodos de austeridad es posible limitar el poder de negociación en materia de salarios. (...) Estas limitaciones son constitucionales siempre que sean de naturaleza temporal y respondan a una situación real de urgencia

83. (...) las limitaciones indefinidas o que impidan que en el futuro los trabajadores puedan negociar sus condiciones laborales, más allá del período previsto por la Ley restrictiva, son, en sí mismas, inconstitucionales.

90. (...) Y si bien las restricciones o prohibiciones a que se negocie el incremento de sus remuneraciones no son en sí mismas inconstitucionales, tal estatus jurídicoconstitucional se alcanza todas las veces en que la prohibición exceda los tres años, que es el lapso máximo para que una medida de esta naturaleza pueda prorrogarse" (Negrita nuestros).

Asimismo, el Tribunal Constitucional, en la sentencia del Expediente 2987-2015-05001-SU-DC-01 de fecha 6 de noviembre de 2015, pronunciada con posterioridad a la sentencia de inconstitucionalidad del artículo 6 de la Ley de Presupuesto del Sector Público para el ejercicio 2013, en su fundamento noveno señaló:

"Cabe precisar, que respecto a la prohibición de negociación colectiva para incrementos salariales de los trabajadores de la administración pública, el Tribunal Constitucional en los procesos de inconstitucionalidad acumulados (Expedientes $N^{o}$

${ }^{34} \mathrm{Al}$ respecto, puede verse en otro contexto el trabajo de Tomás Salas Franco, La representación sindical de los funcionarios públicos en las administraciones públicas, en Los Sindicatos, homenaje al profesor Don Jaime Montalvo Correa con motivo de su jubilación, Luis Enrique De la Villa Gil e Ignacio GarcíaPerrote Escartín (Coordinadores), Lex Nova- Thonsosn Reuters, Valladolid, octubre 2004, p.201-219. 
003-2013-PI/TC, 0004-2013-PI/TC y 0023-2013-PI/TC) (...), ha emitido Sentencia de fecha tres de setiembre de dos mil quince, declarando fundada en parte, por el fondo, las demandas de inconstitucionalidad interpuestas contra el artículo $6^{\circ}$ de la Ley $N^{o}$ 29951, Ley de Presupuesto del Sector Público para el Año Fiscal 2013, declarando la inconstitucionalidad de las expresiones “(...) beneficios de total indole (...)” y (...) mecanismo (...)", en la medida que no se puede prohibir de modo absoluto el ejercicio del derecho fundamental a la negociación colectiva en la Administración Pública, que implique acuerdos relativos a los incrementos remunerativos, así como inconstitucionales, por la Forma del Segundo Párrafo de la Quincuagésima Cuarta Disposición Complementaria Final de la Ley $N^{o} 29812$ y del Tercer Párrafo de la Quincuagésima Octava Disposición Complementaria Final de la Ley $N^{o} 29951$; en consecuencia; este agravio es infundado" (Subrayado y negrita nuestros).

Finalmente, en la sentencia del Tribunal Constitucional del 26 de abril de 2016, recaída en los expedientes 0025-2013-PI/TC, 0003-2014-PI/TC 0008-2014-PI/TC y 00172013-PI/TC, se declara inconstitucional las restricciones al derecho a la negociación colectiva de los servidores públicos, contenidas en la Ley 30057, Ley del Servicio Civil, señalando al respecto que:

"166. (...) no puede ser interpretado en el sentido de que se excluya la materia económica del ámbito de la negociación colectiva puesto que la expresión “condiciones de trabajo y empleo" incluyen también los aspectos económicos de toda relación laboral.”.

169. Asimismo, este Tribunal considera que la disposición legal objetada que prohíbe la negociación colectiva para mejorar la compensación económica, que permite su uso únicamente en el caso de las compensaciones no económicas, o que sanciona con nulidad la contrapropuesta o propuesta sobre compensaciones económicas resultan inconstitucionales por contravenir el derecho a la negociación colectiva y el deber de su fomento (...)” (Negrita nuestros).

Como se aprecia de la lectura de los artículos referidos a la negociación colectiva en la Ley del Servicio Civil, no se establece un plazo determinado, que debería ser excepcional, para restringir las materias económicas del contenido negocial. Por el contrario, se planteaba la limitación como permanente y, por lo tanto, también fue declarado inconstitucional ${ }^{35}$.

Es decir, con el Pleno Jurisdiccional recaído en los expedientes 0025-2013-PI/TC; 0003-2014-PI/TC, 0008-2014-PI/TC, 0017-2014-PI/TC que versó sobre la Ley de Servicio Civil, se desbarató los límites a la negociación colectiva en el sector público que colocaba la citada norma en materia de incremento de remuneraciones.

Además, bajo una interpretación sistemática indicó el Tribunal, que, si bien expresamente no se señala la negociación colectiva como derecho en el artículo 42 refiriéndose a este grupo trabajadores, este está reconocido por la esencia triangular del Derecho Colectivo del Trabajo. Modificando así la norma y subrayando la petición al

35 Por ello, se puede inaplicar la parte pertinente de los artículos 31.2, 40, 42 y 44 b) de la Ley del Servicio Civil, por contravenir el derecho a la negociación colectiva consagrado constitucionalmente. 
Congreso de la República a crear una norma que regule este proceso negocial. Cabe señalar, que el plazo señalado al legislativo ya se ha sobrepasado.

\subsection{En materia de los derechos fundamentales laborales de carácter procesal}

En el ámbito del proceso laboral en general "se reproducía el desequilibrio existente entre las partes contratantes en el contrato de trabajo, que se intentaba corregir por medio del derecho sustantivo" (Sagardoy, 2003 p.823). Entonces, éste nace de la necesidad de garantizar y plasmar los derechos sustantivos de los trabajadores en caso de ser desconocido, incumplido o conculcado. En esto radica su importancia cada vez mayor por los fines que se propone y las consecuencias que trata de evitar.

En ese sentido, el proceso laboral se concreta en el conjunto de normas, principios e instituciones que constituyen la legislación procesal, por cuyo medio el Estado, ejercitando su función jurisdiccional, administra justicia laboral ${ }^{36}$. De esta manera surge un nuevo Derecho Procesal que reúne determinadas características Así, el proceso laboral tiene por objeto resolver los conflictos de trabajo mediante los órganos jurisdiccionales ${ }^{37}$. Por ello, la importancia del proceso laboral es evidente. Pero el carácter protector de la ley sustantiva de trabajo, mientras tanto, se proyecta sobre el procedimiento e inspira el criterio hermenéutico adoptado por el juez, no sólo al formularse la sentencia sino también al conducir el proceso ${ }^{38}$.

Es decir, el proceso en general vendría a ser un conjunto de reglas, formas y actos para la consecución de ciertos fines, fundamentalmente la solución de un conflicto a través del Derecho como categoría de la mediación social ${ }^{39}$. Recordemos que en general "la actividad mediante la cual se desarrolla en concreto la función jurisdiccional se llama proceso". (Tullio, 1971, p. 25).

${ }^{36}$ En la jurisprudencia del Tribunal Constitucional Español se enfatiza ese carácter. “(...) superando tendencias que creían que el Derecho Procesal era un conjunto de normas neutras y aisladas del Derecho sustantivo..." (Sentencia del 25 de enero de 1983).

${ }^{37}$ Que reúne determinadas características. Podemos señalar:

- Es expresión del Derecho sustantivo (Derecho del Trabajo).

- Tiene como fuente de relación directa a los trabajadores, producto de los conflictos colectivos a través de la negociación y convención colectiva que constituyen normas vinculantes.

- Propugna la conciliación como solución equitativa a los conflictos de trabajo.

- Es anti formalista ya que propugna un proceso sencillo, simple y sin mayores formalidades.

${ }^{38}$ Intentando una definición del proceso laboral, puede decirse que es el conjunto de actos procesales que se desarrollan en forma progresiva, sistemática y teleológicamente, que son realizados por el Juez y las partes en cumplimiento de las normas procesales, con el objeto de resolver un conflicto laboral mediante una sentencia emitida por el órgano jurisdiccional. El proceso, en su sentido etimológico, viene de procesus que significa avance y progreso encaminados a algo. Procesalmente podemos traducir la noción de avance y progreso como vocablos en estructura de reglas y actos encaminados a la consecuencia de algo: la sentencia.

${ }^{39}$ Se trata de la regulación normativa de las interacciones, que es lo que convierte al Derecho en una categoría de la mediación social en la perspectiva de Jürgen Habermas, puesto que a los justiciables y a toda la sociedad les interesa que se solucionen los conflictos. 
Por ello, hay que diferenciar entre proceso y procedimiento: el proceso es el todo organizado de actos, el procedimiento constituye tan solo la forma externa del fenómeno procesal, los modos con los cuales deben ser realizados y ordenados los actos que corresponden al proceso. Los actos procesales constituyen el procedimiento, cuyo conjunto recibe el nombre de proceso que tiene como fin resolver el conflicto sometido a la decisión del órgano jurisdiccional mediante un fallo (Parodi, 1996, p. 40). Entonces, se entiende "por procesos laborales los concebidos para resolver litigios en que se invocan reglas y normas relativas al trabajo dependiente" (Diéguez, 1995 p. $635)$.

Esas características del proceso laboral significan contar con principios propios, alteraciones en los conceptos de jurisdicción, competencia, acción, sujetos del proceso, etc. Es lo que trataremos de demostrar al desarrollar, en líneas generales, los temas a continuación.

El proceso laboral era lento, burocrático, formalista y no expeditivo. Además, eran escritos, complejos y se encontraban diseñados para que duren entre 4 a 6 años como mínimo. Los Jueces tenían una competencia reducida y muchos magistrados laborales no tenían la especialidad que se requiere en esta rama especial del Derecho. Asimismo, persiste la crisis del Poder Judicial.

\subsection{En materia de los derechos fundamentales en seguridad social}

En materia previsional, se pueden agrupar las sentencias con un criterio temático y temporal. Así, podemos señalar las tres grandes tendencias en el quehacer del TC, en estos años, las cuales son: la introducción del derecho al mínimo vital, criterios para la movilidad en el sistema previsional y la inserción de la díada trabajo - riesgo. Es decir, las sentencias solo se refieren a los derechos como prestaciones del seguro social contributivo en general sin considerar ningún elemento de la Seguridad Social ${ }^{40}$.

Como sabemos la Seguridad Social no es solamente que algunas personas cobren pensiones o beneficios a fin de mes, es un sistema de protección social universal que debe ser integrante del desarrollo económico y social de un país. Ciertamente hay mucho camino que recorrer, pero también muchos mitos que desvelar si se quiere tener en general niveles mínimos de Seguridad Social.

En ese sentido, es un desafío plantear para nuestro país la implementación de la Seguridad Social para todos ${ }^{41}$; en tanto dista mucho de lo que es la previsión social. Es decir, Seguridad Social para todos se entiende como protección a toda la población especialmente contra riesgos y contingencias sociales; aunque el centro siga siendo el

\footnotetext{
${ }^{40}$ La propuesta de implementación de la Seguridad Social en el Perú, como vía posible, debe surgir de una nueva ecuación de planificación y mercado, a partir de un marco estructural que consagre el ámbito de la competencia del Estado, para enfrentar con éxito los problemas sociales. De esta manera avanzaremos en la construcción de una sociedad que haga compatible el desarrollo material con la equidad social y la democracia. Al respecto, ver mi artículo: Gamarra, Leopoldo, La seguridad social del Estado de necesidad al Estado de bienestar, Revista Laborem, N 15, 2015, pp. 15 - 44.

${ }^{41}$ La perspectiva de la Seguridad Social como derecho humano y política social redistributiva y como ethos normativo que defina valores e ideales.
} 
trabajador, a partir del cual la protección se iría extendiendo a su familia y a otros sectores sociales.

En el sistema de pensiones, deberíamos implementar un modelo mixto de jubilación que combine el sistema público, como componente básico y obligatorio, con el régimen de capitalización plena e individual como complemento. Es decir, un sistema público con una pensión básica y prestación definida bajo un sistema de reparto y el de capitalización, otorgaría un monto adicional sobre los aportes voluntarios. Tendría dos componentes, superando el modelo dual o paralelo.

Respecto al sistema de salud, es fundamental el acceso universal real a los servicios de salud y a la Seguridad Social, con participación ciudadana y del Estado. Como una nueva vía de desarrollo del sistema de salud en el Perú, que consiga los objetivos básicos de toda Seguridad Social mediante la acción determinante del Estado, sin que ésta excluya la iniciativa privada.

\section{Conclusión}

Con la Constitución de 1993 se precisó las funciones del TC y frente a los grandes cambios que afectaron especialmente a los derechos laborales, como a la estabilidad y los derechos colectivos en general, en toda la década 90, recién desde el 2000 contamos con sentencias relevantes del TC en defensa de la constitucionalidad de los derechos fundamentales de los ciudadanos.

En efecto, luego de la caída del régimen autoritario y del retorno a la democracia en noviembre del 2000, se ha puesto en marcha un consistente proceso de reforma constitucional a través del Tribunal Constitucional que modificó sustancialmente los temas más importantes de los derechos laborales como la estabilidad laboral y los derechos colectivos.

En esa dirección, el TC en nuestro país es el órgano autónomo e independiente que se encarga del control de la constitucionalidad y al que se le ha confiado la defensa del principio constitucional contra las leyes o actos de los órganos del Estado que pretendiesen socavarlo como ocurrió en la década del 90 que hemos desarrollo en esta monografía. Es así, como el TC, a través del tiempo, se ha colocado como la única institución de asegurar derechos socioeconómicos de los trabajadores reconocidos en la Constitución, ya que como demostramos en este trabajo, la inconstitucionalidad de las normas laborales se usa como la herramienta jurídica más eficaz para lograr el reconocimiento y vigencia de los derechos laborales.

\section{Referencias bibliográficas}

- Grisolia, J. (2013) Manual de Derecho Laboral, Novena edición, Abeledo Perrot, Buenos Aires.

- Amaya, J. (2012) Control de constitucionalidad, Buenos Aires, Astrea.

- Bazán, V., (2010) Derecho procesal constitucional americano y europeo, Buenos Aires, Abeledo Perrot I.

- Blasco A. (1995) La individualización de las relaciones laborales. Madrid, CES, p. 31 y 32. 
- Bryce J. (1988) Constitución flexible y constitucionales rígidas, Centro de Estudios Constitucionales, Madrid, p.7.

- Boza G. (2011) "Nueva regulación de las relaciones colectivas de trabajo", en la Revista Asesoría Laboral, julio 1992, p. 14 - 17.

- Chocrón, A. (2000) Los principios procesales en el arbitraje, José María Bosch editor, Barcelona.

- Cotler, J. (1980) Democracia e integración, IEP, p.51.

- Caballero, J. (2014) La interpretación conforme, México, Porrúa,

- Castilla, K. (2013) ¿Control interno o difuso de convencionalidad? Una mejor idea: la garantía de los tratados, Anuario Mexicano de Derecho Internacional, México, núm. 13.

- De Vergottini, G. (1985) Derecho Constitucional Comparado, Ed. Espasa, Madrid.

- Diéguez G. (1995) Lecciones de Derecho del Trabajo, Ed. Marcial Pons, Madrid, 4ta edición, p.635

- Ercilio F y Valladares K. (2013) Desregulación y discriminación en las relaciones laborales, los sectores textiles, confecciones y agroexportaciones en el Perú 1978-2011. CEDAL Lima.

- Fazzalari, E. (2000) L'arbitrato nell'era della “mondializzazione en Rivista dell'arbitrato, $\mathrm{N}^{\circ}$ 2, Giuffré editore, Varese.

- Flores, A. (2014) El control de convencionalidad y la hermenéutica constitucional de los derechos humanos, México, Porrúa.

- Gamarra, L. y La Hoz, R. (1995) Conflictos Colectivos de Trabajo y Sistemas de Solución, Universidad Nacional Mayor de San Marcos, Facultad de Derecho y Ciencia Política, Instituto de Investigación de Derecho del Trabajo y de la Seguridad Social, Lima, p. 221.

- Gamarra, L. (2016) La negociación colectiva en el Perú: de la confrontación al diálogo social, en Diálogo y Concertación Laboral, Revista del Consejo Nacional de Trabajo y promoción del Empleo, Ministerio de Trabajo y Promoción del Empleo, Año 2, N² 2, junio, p. 31.

- Gamarra L y Alemán F, (1998) Dos Modelos de Reforma Laboral: Perú y España, Edial, Lima.

- Garavito, C. (1996) Intervención del Estado en el mercado de trabajo: Ley de Fomento del Empleo, documento de trabajo $\mathrm{N}^{\mathrm{o}}$ 125, Departamento de Economía de la Pontificia Universidad Católica del Perú, marzo, p. 18.

- Girao, J. (2015) Las relaciones colectivas de trabajo a partir del arbitraje potestativo: un balance general, en la Revista Laborem, $N^{\circ}$ 15/2015, Sociedad Peruana de Derecho del Trabajo y de la Seguridad Social, p. 331.

- García V. (2005) "El Tribunal Constitucional: la interpretación constitucional y las sentencias manipulativas - interpretativas normativas", en la Revista Laborem de la Sociedad Peruana de Derecho del Trabajo y de la Seguridad Social, No 5 , p. 17 y ss.

- García, S. y Castañeda, M (coords.) (2009), Recepción nacional del derecho internacional de los derechos humanos y admisión de la competencia contenciosa de la Corte Interamericana, México, UNAM, Instituto de Investigaciones Jurídicas.

- Garro, A. (1990) El arbitraje en la ley modelo propuesta por la Comisión de las Naciones Unidas para el derecho mercantil internacional y en la nueva legislación española de arbitraje privado: un modelo para la reforma del arbitraje comercial en América Latina en Arbitraje comercial y laboral en Central América, Transnational Iuris Publications Inc., New York.

- Gaspar, S. (1998) El ámbito de aplicación del arbitraje, Aranzadi editorial, Pamplona.

- Grade://elcomercio.pe/economia/peru/existen-contratos-temporales-peru-noticia-Dic. 2017

- Hudskopf, O. (2006) El control difuso en la jurisdicción arbitral. Título publicado en Diálogo con la Jurisprudencia. Actualidad, Análisis y Crítica Jurisprudencial, N 91, Año II. Lima.

- Hesse, K. (2011) Escritos de derecho constitucional, Madrid, Centro de Estudios Constitucionales. 
- Huerta, C. (1998) El control de la constitucionalidad, análisis del artículo 105 constitucional, Boletín Mexicano de Derecho Comparado, México, año XXXI, núm. 93, setiembrediciembre.

- Jaramillo M. (2014) Crecimiento y segmentación del empleo en el Perú, 2001-2011. Lima: GRADE.

- Landa C. (1995) Del Tribunal de Garantías al Tribunal Constitucional: el caso peruano, en la Revista Pensamiento Constitucional, Vol. 2, Núm. 2, p. 79.

- Landa, C. y Santisteban, J. (2010) El arbitraje en la constitución de 1993 y en la jurisprudencia del tribunal constitucional, Revista peruana de Arbitraje $\mathrm{N}^{\circ} 2$.

- Manrique, N. (2002) El Tiempo del Miedo, la violencia política en el Perú 1980 - 1996, Fondo Editorial del Congreso del Perú, Lima, p. 260.

- Matheus, C. (1999) El litisconsorcio necesario, Ara editores, Lima.

- Matheus, C. (2001) Entre el mito y la realidad. Hacia un efectivo acceso a la justicia en Legal Express, Gaceta Jurídica, Lima.

- Nino, C. (2003) Introducción al análisis del derecho, 11a. ed., Barcelona, Ariel.

- Novak F. (2005), La Constitución Comentada. De los Tratados, Gaceta Jurídica Primera Edición diciembre, p.766.

- Parodi C. (1996) El Debido Proceso, Ponencia del I Congreso Nacional de Derecho Procesal, Pontificia Universidad Católica del Perú, 7-9 agosto, p. 40).

- Pease, H. (1981) Un perfil del proceso político: a un año del segundo Belaundismo, Desco, Lima.

- Radé, C. (2009), Droit du Travail, 5ta edition, Lextens éditions, París.

- Rubio, M. (2006) El Estado peruano según la jurisprudencia del Tribunal Constitucional, Fondo Editorial PUCP, 2006.

- Sagardoy J. (2003) Prontuario del Derecho del Trabajo, Ed. Civitas, Madrid, 6ta edic., p. 823.

- Silguero, J. (1995) La tutela jurisdiccional de los intereses colectivos a través de la legitimación de los grupos, Dykinson, Madrid.

- Schuldt, J. (1980) Política económica y conflicto social, Lima: Universidad del Pacífico.

- Tullio E, (1971) Manual de Derecho Procesal Civil, Ed. Jurídicas Europa - América, pág. 25.

- OIT, 357 (2010) Informe del Comité de Libertad Sindical. Ginebra, junio de 2010, párrafo 944.

- Vega M. (2001) Editora. La reforma laboral en América Latina. Un análisis comparado. Oficina Regional de la OIT para América Latina y El Caribe, Lima. Primera edición p. 248.

- Villavicencio A. (1999) La Libertad Sindical en el Perú, Documento de la OIT, N 114.

- Ugarteche, O. (1997) El falso dilema, América Latina en la economía global, Lima, Fundación Friedrich Ebert - FES, p. 20 